\title{
Prolonged azathioprine treatment of non-remitting multiple sclerosis
}

\author{
J.A.R OS E N \\ From the Presbyterian-University Hospital, Pittsburgh, and Westmoreland Hospital, Greensburg, \\ Pennsylvania, USA
}

S UMMARY Two groups of 85 and 42 ambulatory patients with moderately advanced nonremitting multiple sclerosis were treated for six to 14 and three to six years with daily azathioprine. Less than $10 \%$ of these patients became confined to a wheelchair. This far exceeds any possible result in a group of non-remitting multiple sclerosis patients not so treated.

There has been convincing evidence for at least a partial role of immune mechanisms in the production of multiple sclerosis for many years. These data still seem relevant despite the great proliferation of other data relating to the pathogenesis of this disease (Jersild et al., 1972; Lancet leaders, 1974, 1976; Miyamoto et al., 1976). In the mid 1960 s the exact nature of the immunological mechanisms of multiple sclerosis were unclear. However, it seemed reasonable to attempt chronic immunosuppressive therapy with agents more potent and reliable than corticosteroids and ACTH, analogous to the data from experimental allergic encephalomyelitis (Hoyer et al., 1962; Paterson and Drobish, 1969; Vogel and Calabresi, 1969). Therefore, patient selection criteria and a chronic treatment protocol using purine analogues were established in 1964 and continued to the present. This report mainly concerns the effect of this treatment on patients with non-remitting multiple sclerosis treated for a minimum of six years. The study was under way for several years before the efficacy of this treatment was realised. When this was discovered in 1972, a more select and controlled study was undertaken, as well as the continuation of the larger group.

\section{Methods}

All those treated were private patients of the author during the period from 1964 to 1978 (Western Pennsylvania, latitude 40 degrees north).

Address for reprint requests: Dr James A. Rosen, Associate Professor of Clinical Neurology, University of Pittsburgh, School of Medicine, c/o RD 2 Box 645, Greensburg, Pa 15601, USA.

Accepted 10 October 1978
All patients with probable or definite multiple sclerosis by the criteria of Schumacher et al. (1965) and defective colour vision (Rosen, 1965) were considered for the study. In the first series, 48 of the patients were women, 37 were men. Thirtythree were between 25 and 35 years of age, and 52 were in the 35 to 45 year age group at the onset of treatment with azathioprine. All the patients had had the disease, by history, for at least four years. At the time of their inclusion in the study they had all shown objective evidence of worsening of their disease in the previous year. Patients with a static course for over one year before consideration for the study were excluded; so were those patients with a remission within three years of the study.

The average patient in this pilot study of 85 patients was 38 years old at the onset of immunosuppressant treatment. There were 70 whites, six blacks, one American Indian, one Korean, and one Chinese-American. They had had the diseâse for an average of eight years, and all were in the progressive phase of either a biphasic or monophasic disease course. This progression was continuous, there being no instance of three consecutive semiannual examinations showing a static or remitting course just before treatment. Most patients had evidence of optic nerve, medial longitudinal fasciculus, sensory, and sphincter problems; but corticospinal, with or without cerebellar, motor disability of a significant degree was considered essential for inclusion in the study. If patients were not excluded for any reason (Table 1), the theory of the treatment and the possible risks, including death, were then explained to the patients and informed consent obtained. 
Table 1 Reasons for exclusion from the study

Reason

Age greater than 45 or less than 25 yr (30-50 yr in second study) Symptoms of multiple sclerosis of less than five years' duration Significant improvement in condition within three years of initial evaluation

Retrobulbar neuritis only

Insignificant motor disability

Normal colour vision

Unreliable patient

Disabling dementia

Possibility of leaving area within five years

Class 1 patients

Bedridden patients

Unreliable family unit or patient

Difficult access to a medical laboratory

Treatment was started with 6-mercaptopurine (6-M-P) $50 \mathrm{mg}$ twice daily by mouth, from 19641968 , and changed to azathioprine (Imuran) $50 \mathrm{mg}$ twice daily from 1968 to the present. Weekly laboratory studies (complete and differential blood counts, serum glutamic acid transaminase, and blood urea nitrogen) were obtained for the entire treatment period. The dose of azathioprine was adjusted to yield a WBC of approximately $3500 / \mathrm{mm}^{3}$ and $/$ or a differential count of less than $20 \%$ lymphocytes. The haematocrit was kept above $35 \%$, serum glutamic acid transaminase below $75 \mathrm{iu} / 1$, and the blood urea nitrogen level below $250 \mathrm{mmol} / \mathrm{l}$. Dosage adjustments resulted in a total daily dose of between 100 and $200 \mathrm{mg}$ of azathioprine. Exacerbations were treated with ACTH gel 80 units intramuscularly every 12 hours for 14 days. If this was contraindicated or refused, the azathioprine dose was raised to $300 \mathrm{mg}$ daily for two weeks, and then the pre-exacerbation dosage was resumed. This last procedure was omitted if there was a history of drug-induced leucopenia (below $3000 / \mathrm{mm}^{3}$ ) since the onset of treatment.

Follow-up was by periodic examination in most cases and occasionally by telephone or post. The results reported here represent the latest (1978) evaluation of the patients. They were evaluated in many ways, but for the purpose of this study they were classified (Table 2) by a modification of the

Table 2 Modified McAlpine mobility scale

\begin{tabular}{ll}
\hline Class & Description \\
\hline 1 & $\begin{array}{l}\text { Unrestricted-symptomatic but without restriction for } \\
\text { employment and domestic life }\end{array}$ \\
2 & $\begin{array}{l}\text { Restricted-able to walk unaided for short distances, and } \\
\text { able to use public transport } \\
\text { Markedly restricted-unable to walk without support } \\
\text { even for short distances, or to use public transport } \\
\text { Immobile-confined to wheelchair } \\
5\end{array}$ \\
\hline
\end{tabular}

McAlpine mobility scale (McAlpine and Compston, 1952). In the first study, if a patient was lost to follow-up in less than six years, or if treatment was discontinued because of toxicity, that patient was arbitrarily considered to be a class 4 result.

In 1972, a more limited and controlled study was undertaken. Forty-two white women between the ages of 35 and 50 years were selected and randomised into azathioprine treatment and control groups. These were new patients, not included in the previous study. In these subjects the age of onset of the disease was more than 30 years, and they had had no remissions, improvement, or cessation of progression of the disease for at least three years before treatment. In other respects they were similar to the pilot group regarding characteristics and exclusions. This group has now been under observation for three to six years. The average follow-up period in the pilot series was nine years. In the randomised study, the average follow-up was 4.5 years (Table 3 ).

Table 3 Follow-up time

\begin{tabular}{|c|c|c|}
\hline Time (years) & Randomised group & Pilot study \\
\hline $3-4$ & 4) & - \\
\hline $4-5$ & 27 average 4.5 years & - \\
\hline $5-6$ & 11 is & - \\
\hline $6-8$ & - & $56)$ \\
\hline $8-10$ & - & 15 average 9 years \\
\hline $10-12$ & - & $9\}$ \\
\hline \multirow[t]{3}{*}{$12-14$} & - & 5 \\
\hline & - & - \\
\hline & 42 & 85 \\
\hline
\end{tabular}

\section{Results}

The results of the original treatment effort are listed in Table 4 and expressed solely in terms of mobility after six to 14 years of treatment with azathioprine. As stated previously, the results are not favourably influenced by defaulters since these were considered to be class 4 results. It is seen that

Table 4 Results of original study

\begin{tabular}{|c|c|c|}
\hline Mobility rating & At onset of azathioprine & In 1978 \\
\hline $\begin{array}{l}1 \\
2 \\
3 \\
4 \\
\text { Bedridden } \\
\text { Dead }\end{array}$ & $\begin{array}{c}0 \\
23 \\
52^{*} \\
10 \\
0 \\
-\end{array}$ & $\left.\begin{array}{c}0 \\
21 \\
50 \\
12 \dagger \\
2 \\
0\end{array}\right\} 16 \%$ \\
\hline Total & 85 & 85 \\
\hline
\end{tabular}

*Four patients lost to follow-up were class 3 at onset.

+Four patients who stopped treatment because of life-threatening drug reactions and four patients lost to follow-up are included in this number. 
less than $10 \%$ of the patients treated progressed from an ambulatory to an immobile status.

In the later randomised study begun in 1972 and observed most recently in January 1978, 65\% of the untreated cases are in wheelchairs (or worse) compared to only $9 \%$ of the azathioprine treated group (Table 5). The latter percentage is further weighted by one case of recurrent herpetic stomatitis and finger ulceration requiring discontinuation of the drug and rapid decline to class 4 status after this. In this latter group, there was one patient with erythema nodosum who deteriorated after withdrawal of azathioprine. She improved to even better than pretreatment status when only $25 \mathrm{mg}$ of drug daily was restarted (after the streptococcal aetiology of her exanthem was discovered).

Table 5 Results of randomised study

\begin{tabular}{|c|c|c|c|c|}
\hline \multirow{2}{*}{$\begin{array}{l}\text { Mobility } \\
\text { rating }\end{array}$} & \multicolumn{2}{|l|}{1972} & \multicolumn{2}{|l|}{1978} \\
\hline & Untreated & Treated & Untreated & Treated \\
\hline $\begin{array}{l}1 \\
2 \\
3 \\
4 \\
\text { Bedridden } \\
\text { Dead }\end{array}$ & $\left.\begin{array}{c}0 \\
0 \\
20 \\
0 \\
0 \\
0\end{array}\right\} 0 \%$ & $\left.\begin{array}{c}0 \\
0 \\
22 \\
0 \\
0 \\
0\end{array}\right\} 0 \%$ & $\left.\begin{array}{c}0 \\
0 \\
7 \\
10 \\
2 \\
1\end{array}\right\} 65 \%$ & $\left.\begin{array}{c}0 \\
2 \\
18 \\
2 \\
0 \\
0 \\
-22\end{array}\right\} 9 \%$ \\
\hline
\end{tabular}

The following side effects, all reversible with either discontinuation or adjustment of dosage of azathioprine, were encountered. Effects requiring discontinuation of the drug included lupus-like syndrome-rash, adenopathy, haemolytic anaemia -(two cases), severe leucopenia-below $2500 / \mathrm{mm}^{3}$ -(one case), intractable vomiting, occurred with 6-M-P-(one case), and herpetic stomatitis-one case). Effects relieved by dosage adjustment or time were mild alopecia-(three cases), rash-(two cases), transient nausea and vomiting-(22 cases), anaemia-haematocrit below 35\%-(two cases), leucopenia-above $2500 / \mathrm{mm}^{3}-(12$ cases $)$, increased serum glutamic acid transaminase-above $75 \mathrm{iu} / 1$-(four cases), and purpura-(one case). There were no deaths or malignant neoplasms.

\section{Discussion}

The wide variation in the natural history of multiple sclerosis makes controlled trials difficult to set up and interpret (Lancet, 1976). This study is, of course, vulnerable to criticism for not involving more control subjects, double blind procedures, and multiple observers. However, an attempt has been made to offset this deficiency by the later study and by limiting the results reported from the first study to the drug's apparent effect on the mobility status of the patients in terms of the McAlpine mobility scale and by a comparison with a compilation of prognostic data from many sources previously reported (Allison, 1950; MacLean and Berkson, 1951; Alexander et al., 1958; McAlpine, 1961; Hyllested, 1961; Bauer and Firnhaber, 1964; Leibowitz et al., 1964; Fog, 1966; Fog and Linneman, 1970; Kurtzke et al., 1970; Gudmundsson, 1971). These studies (Table 6), when averaged, revealed that over $40 \%$ of multiple sclerosis patients reach motor incapacitation within 10 years of the onset of the disease, and somewhat fewer in five years. They also reveal that over $30 \%$ are dead within 10 years of onset. The more recento data from the Goteborg Conference (Anderson? et al., 1972) reveals a static course in a much higher percentage of untreated cases; but, nothing approaching the $90-93 \%$ continued ambulation and zero death rate achieved in the azathioprinetreated groups in these two studies. A comparison of the Goteborg Conference material and the natural history data in Table 6 still leave the definite impression that the immunosuppressant therapy used in the studies reported in this paper achieved a result unobtainable in those not so treated. To further emphasise the seeming efficacy

Table 6 Selected natural history data from published reports

\begin{tabular}{|c|c|c|c|c|c|}
\hline Reference & $\begin{array}{l}\text { Number of } \\
\text { patients }\end{array}$ & $\begin{array}{l}\text { Motor } \\
\text { incapacitation } \\
\text { five years after } \\
\text { symptom onset } \\
(\%)\end{array}$ & $\begin{array}{l}\text { Motor } \\
\text { incapacitation } \\
\text { 10 years after } \\
\text { symptom onset } \\
(\%) \\
\end{array}$ & $\begin{array}{l}\text { Death within } \\
10 \text { years of } \\
\text { symptom onset } \\
(\%)\end{array}$ & $\begin{array}{l}\text { Death or motor } \\
\text { incapacitation } \\
\text { within } 10 \text { years of } \\
\text { symptom onset } \\
(\%)\end{array}$ \\
\hline Gudmundsson (1971) & 83 & - & 29 & 4 & 33 \\
\hline McAlpine (1961) & 241 & - & 33 & 14 & 47 \\
\hline Leibowitz et al. (1964) & 284 & - & 49 & - & - \\
\hline Bauer and Firnhaber (1964) & 311 & 29 & 48 & 2 & 50 \\
\hline Lazarte (1948) & 98 & 7 & 21 & 31 & 52 \\
\hline Kurtzke et al. (1970) & 527 & - & - & 9 & - \\
\hline Fog (1966) & 73 & - & 80 & - & - \\
\hline Hyllested.(1961) & 2731 & - & - & 8 & - \\
\hline Bramwell (1917) & 200 & - & - & 53 & - \\
\hline MacLean and Berkson (1951) & 418 & 35 & 45 & 18 & 63 \\
\hline
\end{tabular}


of this treatment, it is recalled that Charcot and many authors since have emphasised the biphasic nature of the course in most multiple sclerosis cases. After a period of fluctuation, the course usually becomes progressive and totally disabling between years five and 10 of the disease (Fog and Linneman, 1970; Schuller, 1973; Broman et al., 1974).

Only patients with non-remitting multiple sclerosis were included in this study - that is, those who had not improved in any objective way and had not become static for at least three years. The exclusion of those not in the 25 to 45 year age group at the onset of treatment was an attempt to avoid biasing the results by treating those whose disease was too likely to remit (young) or to become static because of older age. When the class 4 (wheelchair bound) patients in 1978 are analysed, it is noted that four patients were reported as class 4 merely because they were lost to follow-up, and four changed from class 2 or 3 to class 4 shortly after azathioprine was discontinued. Therefore, less than $5 \%$ of the patients who actually were treated with the drug for the entire observation period of six to 14 years, and were still taking it in 1978, have actually progressed to wheelchair status. These results have held at less than $10 \%$ total disability in the more than 200 patients now being treated, but not all reported in this pilot study because of insufficient observation time (less than six years). The toxicity has also remained about the same, and no deaths or malignant neoplasms have, as yet, occurred. A possibly significant observation in this study, although not statistically valid, is that of marked increase in incapacity within a short perod of time in every case in which azathioprine therapy was discontinued because of toxicity, fear, or other reasons. The randomised study was limited to the 35 to 50 year age group because it is known that this higher age of onset is much more likely to produce a rapid, progressive, unremitting course (Muller, 1951).

When this study was begun in 1964, the major emphasis in multiple sclerosis research was on immune mechanisms (Paterson and Drobish, 1969; Lancet, 1974; Adams, 1975). At the present time, we are confronted with a bewildering array of data linking multiple sclerosis to immunodeficiency (Miyamoto et al., 1976), specific tissue types (Jersild et al., 1972), other types of genetic phenomena (Jersild et al., 1972; Lancet, 1974), various relationships to the measles virus (Lancet, 1974; Miyamoto et al., 1976), and other virological data (Lancet, 1976). There are even data suggesting the efficacy of treatment with a rationale exactly opposite to the present study-namely, using substances capable of augmenting immune mechanisms (Fog et al., 1975; Salk, 1978), rather than suppressing them. The immunological data have spread from humoral to cell-mediated immunity and the relationship of multiple sclerosis to $T$ cells; $B$ cells (Lisak, 1975), measles and other viruses (Miyamoto et al., 1976), geographical factors (Lancet, 1976), and so on.

The difference in the results of this study, when compared with those of previous treatment attempts with azathioprine, 6-mercaptopurine, and cyclophosphamide (Neumann and Ziegler, 1972; Silberberg et al., 1973; Swinburn and Liversedge, 1973; Drachman et al., 1975), is possibly related to the much longer duration of this study, the much larger patient sample, and the limitation of the reporting of the results to the criteria of motor capacity. I suggest that if these workers had recorded their results in terms of lack of progression rather than improvement, their results might have been quite similar to those reported here. The somewhat more aggressive nature of the treatment in this study, because of the very close laboratory surveillance, might also be a partial explanation for the difference. Another difference is the limitation of this study to non-remitting cases-that is, those that had not shown any improvement for at least three years. The recent study by Lance's group (Lance et al., 1975) was somewhat more encouraging. Millar's (1975) work with the linolenic acid treatment of multiple sclerosis offers additional evidence for the immunosuppressant approach.

Finally, I feel that the definite risk of serious side effects or even the remote possibility of malignant neoplasm and death is justified in view of the available data on the risk of death from multiple sclerosis. In addition to the death data included in Table 6, Muller (1949) found that 50\% of multiple sclerosis patients are dead within 10 years of the onset of the progressive phase of the disease; and Hyllested (1961) found a figure of $64 \%$ for the same period. Despite the fact that the mobility of a few patients was modestly improved during treatment, I wish to emphasise that this regimen is not presented as a possible method for improving the status of multiple sclerosis patients, but rather as a stopgap measure to prevent progression of the disease until more definitive treatment is discovered. I, therefore, conclude that the data presented in this report and the seemingly acceptable degree of toxicity (with the close clinical and laboratory surveillance used here) seem to justify further studies on long term immunosuppression in multiple sclerosis. 


\section{Appendix}

REPRESENTATIVE CASE REPORTS

Case $1 R F$, a 39 year old woman At age 18 years this lady had an acute onset of vertical diplopia, ataxia, and a sensory level to T4 dermatome bilaterally. This subsided in six months. At age 23 years she had a sudden onset of left crural monoparesis with improvement in two weeks. From age 23 to 28 years she had seven attacks of neurological illness manifested variously by diplopia, decreased vision, dysarthria, Lhermitte's sign, limb and gait ataxia, unilateral and bilateral weakness, and various sensory deficits as well as sphincter and sexual symptomatology. On numerous occasions cerebrospinal fluid examination revealed 5 to 50 lymphocytes per $\mathrm{mm}^{3}$ normal total protein and IgG concentrations of 14 to $30 \%$ of the total protein.

At age 28 years, examination revealed a mild organic mental syndrome manifested by facetiousness, decreased memory, and logorrhoea as well as pseudoeuphoria with underlying depression. There were bilateral Marcus Gunn pupils, moderate bilateral optic atrophy, and marked decrease in colour vision bilaterally. There was a left internuclear ophthalmoplegia, and both horizontal and vertical nystagmus in all gaze directions. There was a typical Lhermitte's sign and a sensory level for pain at T4 dermatome bilaterally. There was moderate intention tremor of the left upper extremity, moderate heel-to-shin dysmetria of both lower extremities, and moderate gait ataxia. There was generalised hyperreflexia, bilateral Babinski signs, and a hyperactive jaw jerk. There was moderate spastic paraparesis and moderately severe right hand weakness. Her mobility status was class 2.

Routine laboratory studies were normal. The EEG revealed intermittent theta activity bilaterally. The scan of the brain revealed very small periventricular plaques bilaterally. Sensory and visual evoked potential studies were definitely abnormal. The cerebrospinal fluid IgG was $22 \%$ of the total protein (normal for laboratory less than $14 \%$ ). There were 12 lymphocytes per $\mathrm{mm}^{3}$ in the spinal fluid and a total protein of $0.72 \mathrm{~g} / 1$. The initial haemogram revealed a haematocrit of $42 \%$, WBC $5600 / \mathrm{mm}^{3}$ with $65 \%$ polymorphs and $30 \%$ lymphocytes.

From age 28-32 years, the patient had no further remissions or sudden worsening of her attacks. However, during this period her mental status worsened as did her vision, ataxia, weakness, and urinary symptoms. At age 32 years, her examination was similar to that described above except that she was much worse in the areas cited in the preceding sentence. Her mobility status was now class 3. The patient was started on azathioprine in 1970 at age 32 years, and blood counts and multiple blood chemical analyses were done weekly for six months, then monthly thereafter. The white blood count was kept between 3500 and $4000 / \mathrm{mm}^{3}$ and the haematocrit above $35 \%$ by fluctuating doses of azathioprine. The initial dose was $50 \mathrm{mg}$ twice daily and varied from 100 to $200 \mathrm{mg}$ daily (average $150 \mathrm{mg}$ daily). The patient had no further acute exacerbations of multiple sclerosis for the next six years and neurological examinations at six month intervals showed no discernible changes in her condition. In August 1977, her local physician noted a white blood count of $4200 / \mathrm{mm}^{3}$ and a lymphocyte count of $12 \%$ and stopped her azathioprine therapy without consulting the author. Six weeks later she had a severe worsening of her condition manifested by severe ataxia with inability to walk without a walking aid, total paralysis of the entire left lower extremity, and extension of her sensory level from $\mathrm{T} 4$ dermatome to involve the upper extremities and to cause epicritic sensory dysfunction of the hands and feet for the first time. Her visual acuity markedly worsened, and the internuclear ophthalmoplegia became bilateral. In November 1977, her white blood count without treatment was $8500 / \mathrm{mm}^{3}$ with $68 \%$ polymorphs and $30 \%$ lymphocytes. The spinal fluid contained 98 lymphocytes per $\mathrm{mm}^{3}$, and a protein level of $0.8 \mathrm{~g} / 1$, and the IgG was $34 \%$ of the total CSF protein. She was given $300 \mathrm{mg}$ of azathioprine daily (steroids had previously produced severe emotional changes). Two weeks later, she was walking without support and her vision was markedly improved. Her neurological examination then approximated the examination at age 31 years.

Case $2 S L$, a 54 year old woman At age 38 years this lady noted the gradual insidious onset of ataxia, spastic paraparesis, hypotonic bladder symptoms, dysarthria, and visual blurring. At age 42 years there had been steady progression without remission in the previous four years and at that time she was barely able to walk (class 3 ) with a walking aid because of ataxia and spastic paraparesis. She had loss of vibratory and position sense in the feet but no sensory level. She had Lhermitte's sign. There was a mild bilateral internuclear ophthalmoplegia, bilateral optic atrophy, and bilateral Marcus Gunn pupils. Colour vision was moderately impaired bilaterally. She had severe gait ataxia and minimal cerebellar signs in all four extremities.

The cerebrospinal fluid was acellular with a protein content of $0.28 \mathrm{~g} / 1$. Immunoelectrophoresis 
revealed that $24 \%$ of the total protein was IgG. The patient was started on 6-mercaptopurine, $50 \mathrm{mg}$ daily, and the dosage was adjusted by weekly blood counts and biochemical profiles to give a normal serum aspartate aminotransferase and blood urea nitrogen, a white blood count of $3800 / \mathrm{mm}^{3}$ and a haematocrit of $40 \%$ or more. After two years of this therapy she was switched to azathioprine $50 \mathrm{mg}$ twice daily and continued on this for the next 10 years. Examinations at three to six month intervals from age 42 to 52 years revealed no change in her condition. At age 42 years before treatment, she rated class 3 on the McAlpine mobility scale and remained so 12 years later-a decidedly unusual course for the progressive non-remitting multiple sclerosis pattern in relatively older women.

I would like to thank Margaret Snyder and Beverly Morrell for the bibliography, and Regina Rosen and Barbara Shoaf for manuscript preparation.

\section{References}

Adams, C. W. (1975). The onset and progression of the lesion in multiple sclerosis. Journal of the Neurological Sciences, 25, 165-182.

Alexander, L., Berkeley, A. W., and Alexander, A. M. (1958). Prognosis and treatment of multiple sclerosis. Journal of the American Medical Association, 166, 1329-1331.

Allison, R. S. (1950). Survival in disseminated sclerosis. Brain, 73, 103-120.

Anderson, O., Bergmann, L., and Broman, T. (1972). Models and parameters in clinical description of the course of multiple sclerosis. The International Symposium on Multiple Sclerosis. Acta Neurologica Scandinavica (Supplement 58), 50, 83-87.

Bauer, H. J., and Firnhaber, W. (1964). Prognostic criteria in multiple sclerosis. Annals of the New York A cademy of Seiences, 122, 542-551.

Bramwell, B. (1917). The outcome in disseminated sclerosis. Edinburgh Medical Journal, 15, 16-18.

Broman, T., Bergmann, L., and Anderson, O. (1974). Models and parameters in clinical description of the course of multiple sclerosis. The International Symposium on Multiple Sclerosis. Acta Neurologica Scandinavica (Supplement 58), 50, 84.

Drachman, D. A., Paterson, P. Y., Schmidt, R. T., and Spehlmann, R. F. (1975). Cyclophosphamide in exacerbations of multiple sclerosis. Journal of Neurology, Neurosurgery, and Psychiatry, 38, 592597.

Fog, T. (1966). The course of multiple sclerosis. Acta Neurologica Scandinavica, 42, 608-611.

Fog, T., and Linneman, F. (1970). The course of multiple sclerosis in 73 cases with computer designed curves. Acta Neurologica Scandinavica (Supplement 47), 46, 3-8.
Fog, T., Jersild, C., Dupont, B., Platz, P. J., Svejgaard, A., Thomsen, M., Midholm, S., and Raun, N. E. (1975). Transfer factor treatment in multiple sclerosis. Neurology (Minneapolis), 25, 489-490.

Gudmundsson, K. R. (1971). Clinical studies of multiple sclerosis in Iceland. Acta Neurologica Scandinavica (Supplement 48), 47, 41-46.

Hoyer, L., Good, R., and Condie, R. (1962). Experimental allergic encephalomyelitis: the effect of 6-M-P. Journal of Experimental Medicine, 116, 311360.

Hyllested, K. (1961). Lethality, duration and mortality of disseminated sclerosis in Denmark. Acta Psychiatrica Scandinavica, 36, 553-561.

Jersild, C., Svejgaard, A., and Fog, T. (1972). HL-A antigens and multiple sclerosis. Lancet, 1, 1240.

Kurtzke, J. F., Beebe, G. W., Nagler, B., Nefzger, M. D., Auth, T. L., and Kurland, L. T. (1970). Studies on the natural history of multiple sclerosis. Neurology (Minneapolis), 22, 215-225.

Lance, E. M., Kremer, J., Abbosh, J., Jones, V. E., Knight, S., and Medawar, P. B. (1975). Intensive immunosuppression in patients with disseminated sclerosis. Clinical and Experimental Immunology, 21, 1-12.

Lancet leader (1974). Measles and multiple sclerosis. Lancet, 1, 247.

Lancet leader (1976). Multiple sclerosis. Lancet, 1, 129.

Lazarte, J. (1948). Multiple sclerosis: prognosis for ambulatory and non-ambulatory patients. Proceedings of the Association for Research in Nervous and Mental Diseases, 28, 512-522.

Leibowitz, U., Alter, M., and Halpern, L. (1964). Clinical studies of multiple sclerosis in Israel. Neurology (Minneapolis), 14, 926-932.

Lisak, R. P. (1975). Multiple sclerosis: immunological aspects. Annals of Clinical Laboratory Science, 5, 324-329.

MacLean, A. R., and Berkson, J. (1951). Mortality and disability in multiple sclerosis. Journal of the American Medical Association, 146, 1367-1369.

McAlpine, D. (1961). The benign form of multiple sclerosis. Brain, 84, 186-202.

McAlpine, D., and Compston, N. (1952). Some aspects of natural history of disseminated sclerosis. Quarterly Journal of Medicine, 21, 135-167.

Millar, J. H. D. (1975). Linolenic acid as an immunosuppressive agent. Lancet, 1, 857-859.

Miyamoto, H., Walker, J. E., Ginsberg, A. H., Burks, J. S., McIntosh, K., and Kempe, C. H. (1976). Antibodies to vaccinia and measles viruses in multiple sclerosis patients. Archives of Neurology (Chicago), 33, 414-417.

Muller, R. (1951). Course and prognosis of disseminated sclerosis. Archives of Neurology and Psychiatry (Chicago), 66, 561-570.

Muller, R. (1949). Studies in disseminated sclerosis. Acta Neurologica Scandinavica (Supplement 22), 25, 222-225.

Neumann, J. W., and Ziegler, D. K. (1972). Thera- 
peutic trial of immunosuppressive agents in multiple sclerosis. Neurölogy (Minneapolis), 22, 268-271.

Päterson, R. Y., and Drobish, D. G. (1969). Cyclophosphamide:" effect on experimental allergic encephalomyelitis in Lewis rats. Science, 165, 191192.

Rosen, J. A. (1965). The use of pseudoisochromatic color plate testing in multiple sclerosis. Transactions of the American Neurological Association, 90, 283.

Salk, J. (1978). Immunisation with basic protein in multiple sclerosis. National Multiple Sclerosis Society Newsletter, page 2.

Schuller, E. (1973). Multiple sclerosis: a two phase disease? Acta Neurologica Scandinavica, 49, 453460.

Schumacher, G. A., Beebe, G., Kibler, R. F., Kurland, , L. T., Kurtzke, J. F., McDowell, F., Nagler, B.,
Sibley, W. A., Tourtelotte, W. W., and Wilman, T. L. (1965). Problems of experimental trials of therapy in multiple sclerosis. Annals of the New York Academy of Sciences, 122, 552-568.

Silberberg, D., Lisak, R., and Zweiman, B. (1973). Multiple sclerosis unaffected by azathioprine in pilot study. Archives of Neurology (Chicago), 28, 210212.

Swinburn, W. R., and Liversedge, L. A. (1973). Longterm treatment of multiple sclerosis with azathioprine. Journal of Neurology, Neurosurgery, and Psychiatry, 36, 124-126.

Vogel, C., and Calabresi (1969). Enhanced suppression of experimental allergic encephalomyelitis by combination chemotherapy with duazomycin $\mathrm{A}$ and 6-M-P. Proceedings of the Society of Experimental Biology and Medicine, 131, 251-254. 